\title{
Establishing the credibility of archaeoastronomical sites
}

\author{
Clive Ruggles \\ School of Archaeology and Ancient History \\ University of Leicester, Leicester LE1 7RH, United Kingdom \\ email: rug@le.ac.uk
}

\begin{abstract}
In 2011, an attempt to nominate a prehistoric "observatory" site onto the World Heritage List proved unsuccessful because UNESCO rejected the interpretation as statistically and archaeologically unproven. The case highlights an issue at the heart of archaeoastronomical methodology and interpretation: the mere existence of astronomical alignments in ancient sites does not prove that they were important to those who constructed and used the sites, let alone giving us insights into their likely significance and meaning. The fact that more archaeoastronomical sites are now appearing on national tentative lists prior to their WHL nomination means that this is no longer just an academic issue; establishing the credibility of the archaeoastronomical interpretations is crucial to any assessment of their value in heritage terms.
\end{abstract}

Keywords. Astronomical heritage, Credibility, Chankillo

\section{Introduction}

In 2011, the Republic of Macedonia nominated Kokino, an "ancient observatory" site, for inscription on the World Heritage List. According to the nomination dossier, the site was used throughout the Bronze Age both a ritual area and for observations of the celestial bodies. It featured natural "stone seats" and "stone markers" - gaps and niches in the nearby rocks that ostensibly served as horizon foresights. The problem was that the case for astronomical observations was strongly based upon alignment evidence, and the number of possible observing points and putative astronomical markers could easily be explained away as chance occurrences emphasised by the judicious selection of data. This danger has been very well known in archaeoastronomy since its early development during the 1970s and 1980s. The nomination dossier was rejected.

\section{Credibility as a heritage issue}

The credibility of archaeoastronomical sites, then, is a major issue for astronomical heritage. It is linked to authenticity, since authenticity concerns the degree to which a 'fact' has been proven, or a particular interpretation can be supported, according to current standards in the discipline concerned - e.g. history, archaeology or archaeoastronomy (Ruggles \& Cotte 2010, p. 267).

In a first qualitative attempt to characterise different degrees of archaeoastronomical credibility, the 2010 ICOMOS-IAU Thematic Study (ibid., pp. 270-271) identified four categories as follows:

(1) Generally accepted. Examples include the alignment of the Neolithic passage grave at Newgrange in Ireland upon the rising sun at midwinter, and the solstitial alignment of Stonehenge in the United Kingdom. Both are already on the World Heritage List. 
(2) Debated among specialists. An example here is the interpretation of the circular Caracol at Chichen Itza, Mexico, as an observatory for watching the risings and settings of the sun, planets and stars. Archaeoastronomers continue to debate this interpretation (e.g. Aveni 2006; Schaefer 2006; Ruggles 2014, pp. 363-364). Despite the uncertainties, the building is widely referred to as the "Observatory".

(3) Unproven. An example is the "equinox hierophany" at the Kukulcan pyramid, again at Chichen Itza. This phenomenon attracts many thousands of visitors each year, but there is no convincing historical or contextual evidence to support the conjecture that it was actually deliberate and intentional (Carlson 1999). Despite this, it is widely cited as the principal astronomical connection of the site.

(4) Completely refuted. An example is the interpretation of four rock-painted symbols at Chaco Canyon, USA as a depiction of the 1054 supernova. Cultural evidence strongly suggests that the symbols marked a sun-watching station for native priests (Ellis 1975). Yet the "supernova" was until recently, and may well remain, signposted at the site.

Archaeoastronomical sites are also particularly susceptible to overinterpretation driven by political factors, because they can too easily be seen as demonstrating the intellectual achievements of ancestors. "A sense of national pride or political expediency can sometimes be implicit in claims that, for example, a site is 'the oldest observatory' in a given region. The irony is that such attitudes are founded upon a mistaken belief in a single 'path of progress' towards modern science, something that actually places a negative value onother cultural perspectives and practices" (Ruggles \& Cotte 2010, p. 271).

\section{Chankillo: an extended case study}

Clearly, we need more sophisticated methods to assess archaeoastronomical credibility, and they must reflect the current state of theory and practice in the discipline. Advances in archaeoastronomy over several decades have resulted in the development of a substantial body of theory and practice where the most favoured interpretations depend upon integrating methods from astronomy, anthropology and other disciplines (cf. Ruggles $2011 ; 2014)$. Nonetheless, individual cases can still engender significant methodological debate, as recently regarding Chankillo (Ghezzi \& Ruggles 2011; Malville 2011), which is now on Peru's tentative list. It is also included as an extended case study in the second ICOMOS-IAU Thematic Study (Ruggles \& Cotte 2015).

The thirteen towers of Chankillo, dating to c. 300BC, have been interpreted as a solar observation device by Ghezzi \& Ruggles (2007), an interpretation that is widely accepted although it is disputed by Malville. It is not disputed that the overall plan of the various structures at Chankillo is laid out on a roughly solstitial axis, nor that they had much to do with solar-related cults and rituals. The methodological debate focuses particularly on three issues:

1. The selection of observing points. While it is clear archaeologically that the western observing point - an open doorway facing the towers and surrounded by a scatter of cult offerings - is a place of unique ritual and ceremonial significance, the same is not true of the supposed eastern observing point.

2. The towers are not an exact fit to the sunrise arc. Although December solstice sunrise as viewed from the western observing point occurs directly over the southernmost tower, June solstice sunrise occurs somewhat to the left of the northernmost tower, at the foot of a more distant hill rising to the left away from the towers.

3. The towers are evenly spaced. If the successive gaps between the towers were marking off equal intervals of time through the year, then one would expect the towers to be more closely spaced towards the ends of the line. 
The resolution of such issues depends upon how we factor in archaeological evidence pertaining to the broader cultural context, and also upon a theoretical framework built upon a broad range of anthropological experience. This experience indicates the likely complexity of cultural practices, meaning that observation devices are unlikely to have operated with "western" consistency or exactitude. Cases where we can make a strong case for an astronomical association on the basis of alignment statistics alone - as is true for the seven-stone antas (see paper by Belmonte et al.) - are rare; more often, the strongest interpretation is one supported by multiple lines of evidence and convergent methodologies, often from several different disciplines (Ruggles 2011, pp. 12-13).

\section{Conclusion}

Significant progress has been made within the Astronomy and World Heritage Initiative towards establishing broadly acceptable measures of archaeoastronomical credibility that make sense in the context of the heritage evaluation process. Expert opinion may now be sought from members of the new IAU Commission C4 as part of UNESCO's upstream process, as described in other papers in this Focus Meeting.

At one end of the scale, a claim that an ancient site is strongly related to astronomy, if based on putative astronomical alignments alone, will nearly always be problematic because of data selection issues; a broader interpretative context, from archaeology or history, will generally be crucial in supporting such claims. Comparative studies of sites that raise similar methodological issues, even in very different cultural contexts, may also be important in demonstrating potential outstanding universal value (OUV).

On the other hand, interpretations will always be subject to modification in the light of new archaeological evidence or improved methods. A site such as Newgrange or Stonehenge can clearly be recognised as being of exceptional importance in relation to astronomy even if many of the details of that relationship in the minds of those who built and used it remain unclear, and are likely to remain so.

\section{References}

Aveni, A. F. 2006, in: T.W. Bostwick \& B. Bates (eds), Viewing the sky through past and present cultures (Phoenix: Pueblo Grande Museum), pp. 57-70, 79-83

Carlson, J. B. 1999, Archaeoastronomy, 14(1), 136

Ellis, F. H. 1975, in: A.F. Aveni (ed.), Archaeoastronomy in Precolumbian America (Austin: University of Texas Press), pp. 59-87

Ghezzi, I. \& Ruggles, C. L. N. 2007, Science, 315, 1239

Ghezzi, I. \& Ruggles, C. L. N. 2011, in: C.L.N. Ruggles (ed.), Archaeoastronomy and Ethnoastronomy: Building Bridges between Cultures (Cambridge: Cambridge University Press), pp. $144-153$

Malville, J. McK. 2011, in: C.L.N. Ruggles (ed.), Archaeoastronomy and Ethnoastronomy: Building Bridges between Cultures (Cambridge: Cambridge University Press), pp. 154-161

Ruggles, C. L. N. 2011, in: C.L.N. Ruggles (ed.), Archaeoastronomy and Ethnoastronomy: Building Bridges between Cultures (Cambridge: Cambridge University Press), pp. 1-18

Ruggles, C. L. N. (ed.) 2014, Handbook of Archaeoastronomy and Ethnoastronomy (3 vols.) (New York: Springer)

Ruggles, C. L. N. \& Cotte, M. (eds.) 2010, Heritage Sites of Astronomy and Archaeoastronomy in the Context of the UNESCO World Heritage Convention (Paris: ICOMOS-IAU)

Ruggles, C. L. N. \& Cotte, M. (eds.) 2015, Heritage Sites of Astronomy and Archaeoastronomy in the Context of the UNESCO World Heritage Convention: Volume II (Bognor Regis: Ocarina Books), in press

Schaefer, B. E. 2006, in: T.W. Bostwick \& B. Bates (eds), Viewing the sky through past and present cultures (Phoenix: Pueblo Grande Museum), pp. 27-56, 71-77 